\title{
Comparison of the Amount of Time Allocated by General Dentists and Senior Dental Students to Obtain the History of the Patient's Present Illness
}

Shirazian $\operatorname{sh}^{1}$, Mansourian $\mathbf{A}^{1}$, Vatan pour $\mathbf{M}^{2 *}$, Khezrahdoust $\mathbf{S}^{3}$

${ }^{I}$ Assisstant Professor, Oral Medicine,faculty of dentistry Dept, Tehran University of Medical Sciences

${ }^{2}$ Assistant Professor, Endodontics Dept,Dental Branch of Tehran, Islamic Azad University, Tehran, Iran

${ }^{3}$ Dentist

\begin{tabular}{l}
\hline ARTICLE INFO \\
\hline Article Type \\
Original Article \\
\hline Article History \\
Received: June 2016 \\
Accepted: Sep 2016 \\
ePublished: Jan 2017
\end{tabular}

Keywords:

Medical history,

listening,

illness

\begin{abstract}
Background and aim: Gathering information about the patient's present illness by allocating adequate time to detect the main reason of referral is of utmost importance. This is mostly related to the manner of communication and interaction with the patient and active listening to his/her statements. Registering the information related to the illness and its history has an effective role in patient satisfaction, treatment outcomes, and dental expenses and even in lawsuits against practitioners. Therefore, the present study aimed to compare the average time allocated by general dentists and senior dental students of the dental school of Tehran University of Medical Sciences to obtain the history of the patient's present illness during 2012-2013.

Materials and methods: In this cross-sectional study, 60 senior dental students of the dental school of Tehran University of Medical Sciences and 60 general dentists that had been graduated at least five years ago were selected. Each of them randomly selected three patients and recorded the patients' demographics such as age, gender, education level, and the chief complaint or the main reason of the patient's visit. The duration of the patient's statements regarding the present illness and its history was recorded in seconds in the designed questionnaire. Afterwards, the data were analyzed using T-test and Mann-U-Whitney, Kendall-tau and Chi-square tests.

Results: The average interview time in the students and dentists groups was $24.41 \pm 9.17$ seconds and $27.9 \pm 7.82$ seconds, respectively, which were significantly different according to T-test $(\mathrm{p}=0.003)$. Generally, the longest allocated time equaled 49 seconds, while the shortest interview duration was 6 seconds.

Conclusion: According to the results of the present study, it seems that dentists do not allocate the necessary and adequate time to gather information about the chief complaint and the history of the patient's reason of referral to guide them towards the correct diagnosis and suitable treatment method, and even the passage of time and the level of experience have no effect on this issue.
\end{abstract}

\footnotetext{
Please cite this paper as: Shirazian S, Mansourian A, Vatanpour M, Khezrahdoust S. Comparison of the Amount of Time Allocated by General Dentists and Senior Dental Students to Obtain the History of the Patient's Present Illness. J Res Dent Maxillofac Sci. 2017;2(1):17-24.
}

*Corresponding author:

Email: drvatanpour@gmail.com 


\section{Introduction:}

One of the main components of medical practice is the establishment of a correct and appropriate communication between the practitioner and the patient. Since this relation is bilateral and dynamic, special attention must be paid to some of the obstacles and facilitators of this mutual association, so that an appropriate relationship can be established.

Nowadays, good communication between doctor and patient is considered as one of the main constituents of the clinical competence of a graduate of medical sciences. Therefore, in many educational centers, teaching this skill is included among the main educational programs. ${ }^{(1-4)}$

Communication with patients is comprised of six components, as follows:

1- Introduction and starting the relationship

2- Information gathering

3- Treatment planning

4- Conclusion and ending the session

5- Connection

6- Structured interview

From among these six components, parts 5 and 6 overshadow the first four components and are involved in their execution.

Basically, the diagnosis process is divided to four parts: 1- registration of the chief complaint and medical history, 2- clinical and para-clinical examinations, 3- evaluation of the history and treatment outcomes for guidance towards the correct diagnosis 4- diagnosis of the patient's problem and assessing the probable medical risks during dental treatments. ${ }^{(5)}$

The "chief complaint" which is referred to as the "presenting complaint" in England, is comprised of the problems stated by the patient in his/her own language, and in fact it encompasses the conditions that have forced the patient to refer for treatment. The patient's chief complaint should not be written in scientific language and should be recorded exactly as it is stated by the patient. On the other hand, assessing the history of the patient's current problem which is referred to as the "presenting illness" is also one of the most important items that should be recorded in the patient's clinical file. ${ }^{(2,6-8)}$

Listening is an important skill for practition- ers. Researchers have shown that effective communication skills such as active listening to the patient's statements can be a palliative treatment by itself in many minor illnesses. Also, listening to the main problem(s) of the patient prevents repetitive and unnecessary visits by him/her and that will decrease the workload of the medical staff. $^{(9)}$

Sometimes, the practitioner is unable to earn the patient's trust at the beginning of the relationship or disrupts the conversation through his/her words or deeds during the interview. The later the practitioner interrupts the patient, he/she can present more problems, and it gets less likely for a new problem to appear at the end of the interview. During visits with the internists that had been trained for active listening, this time period equaled 92 seconds on average. ${ }^{(10)}$ Other researches also show that the patient's first complaint is considered as his/her most important problem, while only $23 \%$ of the patients find the permission or the opportunity to complete their statements during a conversation with the practitioner, and from among 51 cases, only in one case the patient completely states all of his/her problems, while in $94 \%$ of cases interruption of the patient's statements by the practitioner during the interview occurs between 18 to $30 \mathrm{sec}-$ onds after the conversation starts. ${ }^{(11,12)}$

The general dentist has the first and the most frequent contacts with the patient. Therefore, before starting any procedure, he/she should gather and study the necessary diagnostic information regarding the main reason of patient's visit and the specifications, quantity and quality of the present illness. Knowing these factors is important from several aspects: sometimes the patient presents multiple problems during the history taking process, which may not be related to the present illness, and this can deviate the path to diagnosis and treatment. ${ }^{(13,14)}$ Moreover, allocating more time and gathering comprehensive information regarding the main reason of patient's visit, the development and duration of the problem, and whether it has interfered with chewing or speech, can improve the relationship between the patient and the practitioner. Also, the incidence of post treatment complications and patient dissatisfac- 
tion which are usually due to incorrect diagnoses and improper treatment methods caused by limited information available to the practitioner about the patient and his/her medical history can be significantly decreased. ${ }^{(15)}$

Assigning more time to find the primary reason of the illness or problem is pleasant for the patient and increases patient satisfaction. ${ }^{(16)}$ In this regard, the manner of posing the question to the patient can also highly influence his/her level of satisfaction. Clear and targeted questions projected by the practitioner have a direct correlation with increased patient satisfaction. However, some researchers have shown that consecutive and direct questions or taking long time for history taking and completing the medical file can be boring for patients and can lead to dissatisfaction due to increased level of anger and anxiety. ${ }^{(16,17)}$

Nevertheless, listening and allocating time to patients is not an easy task, and as long as the practitioner considers no respect or value for the speaker, he/she is not able to actively listen to the statements. ${ }^{(18)}$ According to a study by Bartlett et al, allocation of more time and the experience of the practitioner have no effect on increasing the level of patient satisfaction; however, the common understanding between the practitioner and the patient can more significantly improve patient satisfaction. ${ }^{(19)}$ Also, in a meta-analysis of 60 articles related to patient satisfaction, the researchers found that positive verbal behavior and corporate structure during consultation, rendition of information by the doctor, allocation of adequate time, good medical skills and procurement of information have an effective role in improved patient satisfaction. ${ }^{(20,21)}$

Therefore, the aim of the present study was to compare the amount of time allocated by general dentists and senior dental students to obtain the history of the patient's present illness.

\section{Materials and methods:}

In this cross-sectional study, 60 senior dental students that had been taking the practical oral medicine 3 course and also 60 general den- tists that had been graduated at least five years ago were evaluated. Each of them randomly selected three patients. In total, 180 patients were interviewed by dental students and 180 patients were interviewed by general dentists. Sampling was performed among the two groups of practitioners i.e. all the students taking the mentioned course (census method) and 60 general dentists in Tehran (randomization). After the introduction and explaining the aim of the present research and recording the dentists' demographics such as age, gender and date of graduation, each of the practitioners randomly selected 3 patients and after recording the patients' demographics such as age, gender and education level, they asked about the chief complaint or the main reason of the patient's visit. Afterwards, the quality and quantity of the problem were approached by asking some questions regarding the patient's present illness such as the incidence, reason of occurrence and its duration. (The patients' problems were among common issues such as pain... and none of the patients had pathologic lesions, since the manner of information gathering and history taking in these cases completely differs from ordinary cases).

The students and the dentists were aware of the aim of the study and interview and they were asked to perform a complete interview from the point that the patient starts talking about his/her problem till the end of the conversation. The time was measured and recorded by the observer using a chronometer. Afterwards, the data were analyzed using T-test and nonparametric MannWhitney, Kendall-tau and Chi-square tests using SPSS software.

\section{Result:}

In the present study, 120 individuals in the two groups of practitioners ( 60 dental students and 60 general dentists) performed the interviews and each of them measured and recorded the duration of the interview with the three patients that they had randomly selected from among male and female patients.

A) The practitioners' demographics:

The age range of the 60 dental students was be- 
tween 22 to 31 years (with the average age of $25.8 \pm 1.82$ years), while the age range of the 60 general dentists was between 31 to 51 years (with the average age of $39.69 \pm 5.29$ years). 29 students $(48.3 \%)$ were females and 31 students $(51.7 \%)$ were males. In the dentists group, 25 subjects (41.7\%) were females and 35 subjects $(58.3 \%)$ were males. According to Chi-square test, there were no significant differences in the distribution of the gender of the subjects between the two groups $(p=0.2)$. In the dentists group, the range of the time that had passed since the graduation varied from 5 to 19 years (with the average of $11.15 \pm 3.93$ years).

B) The patients' demographics:

The average age of the patients in the students group was $37.3 \pm 11.77$ years (from 3 to 63 years), while the average age of the patients in the dentists group was $38.23 \pm 10.51$ years (from 6 to 62 years). In addition, 95 patients $(52.8 \%)$ in the students group were females and 85 patients $(47.2 \%)$ were males. In the dentists group, 90 patients $(50 \%)$ were females and 90 patients $(50 \%)$ were males. The average age of the patients showed no statistically significant difference between the two groups of students and general dentists according to T-test ( $\mathrm{p}=0.92$ ).

Moreover, according to Chi-square test, no significant difference was detected in the distribution of the patients' gender between the two groups of practitioners $(\mathrm{p}=0.6)$.

The education level of the patients in the two groups of practitioners is presented in Table 1.

Table 1- The education level of the patients in the two groups of practitioners

\begin{tabular}{lcc}
\hline \multicolumn{1}{c}{$\begin{array}{c}\text { The education level of the } \\
\text { patients }\end{array}$} & $\begin{array}{c}\text { Students group } \\
\text { Percentage } \\
\text { (number) }\end{array}$ & $\begin{array}{c}\text { Dentists group } \\
\text { Percentage } \\
\text { (number) }\end{array}$ \\
\hline Illiterate & $0.6 \%(1)$ & $1.1 \%(2)$ \\
\hline High school diploma & $19.4 \%(35)$ & $12.2 \%(22)$ \\
\hline Diploma & $57.8 \%(104)$ & $66.7 \%(122)$ \\
\hline Associate degree & $6.7 \%(12)$ & $4.4 \%(8)$ \\
\hline Bachelor & $10.6 \%(19)$ & $11.7 \%(21)$ \\
\hline Master's degree or higher & $5 \%(9)$ & $3.9 \%(7)$
\end{tabular}

According to Mann-Whitney test, the education levels of the patients in the two groups did not show any significant statistical differences $(\mathrm{p}=0.51)$.

The average time allocated to obtain the medical history and the chief complaint of the patients in the students group was $24.41 \pm 9.17$ seconds, while in the dentists group, this value equaled $27.9 \pm 7.82$ seconds. The longest time in the students group was 48 seconds, while the shortest allocated time was 6 seconds. The longest assigned time in the dentists group was 49 seconds, while the shortest time equaled 10 seconds. The findings also showed that the average interview time was significantly different between the students and the dentists according to T-test ( $\mathrm{p}=0.003)$.

In addition, a weakly significant negative correlation existed between the interview duration and the age range of the practitioners in the students group, in a way that older interviewers conducted interviews of shorter durations ( $\mathrm{p} \leq 0.001$ and $\mathrm{r}=-0.28$ ), but no significant correlation was detected between the interview duration and the age range of the dentists $(p=0.9)$.

No correlation was detected between the gender of the practitioner and the duration of the interview in any of the practitioners groups ( $\mathrm{p}=0.94$ dentists and $\mathrm{p}=0.85$ students).

A significant negative correlation was detected between the duration of the interview and the age of the patients in the students group $(\mathrm{p}=0.01$ and $\mathrm{r}=-0.18$ ), i.e. older patients had interviews of shorter durations. But no significant correlation was detected between the interview duration and the age of the patients in the dentists group $(\mathrm{p}=0.99)$.

Also, no correlation was detected between the gender of the patients and the duration of the interview in any of the practitioners groups $(\mathrm{p}=0.35$ dentists and $p=0.14$ students).

According to Kendall-tau test, a weak correlation existed between the education level of the patients and the duration of the interview in the dentists group $(\mathrm{p}<0.001)$, but no such correlation was detected in the students group $(\mathrm{p}=0.51)$. 


\section{Discussion:}

In the present study, the average time period allocated by senior dental students of the dental school of Tehran University of Medical Sciences and a group of general dentists to obtain the history of the illness and the current problem of the patient was measured and the effects of some related factors were also evaluated. In the current study, the average time period of $24.41 \pm 9.17$ seconds among the students and the average time of $27.9 \pm 7.82$ seconds among the dentists can be indicative of the absence of relatively high duration of adequate and necessary time allocated to obtain the history of the present illness and to retrieve the necessary information from the patient, and it also emphasizes the necessity of further evaluation of the causes, influential factors and the strategies for solving these problems. Although, Tsimtsiou et al, showed that doctors usually interrupt the patient 18 seconds after he/ she starts speaking and therefore, some important parts of the problem remain unspoken. This time duration was lower than the average time achieved from the two groups of practitioners in the present study. ${ }^{(10)}$

On the other hand, in this study the average patient's speaking time was 23.1 seconds, which is closer to the figures obtained in the current study. ${ }^{(10)}$ In addition, in the present study the longest time period allocated by the students was 48 seconds and for dentists it equaled 49 seconds. Whereas, in the studies by many other authors, the patients had spoken for about 90-95 seconds and had stated their problems. ${ }^{(10)}$ In a study by Labbaf et al the average interview time was stated to be 52-53 seconds, which differs from the statistics obtained in the present study. ${ }^{(22)}$ These observations indicate the importance of a proper conduct, establishment of a respectful and suitable relationship, allocation of time by the practitioner and elucidating the manner of performing the treatment.

Multiple studies indicate that many physicians and dentists do not effectively communicate with their patients. ${ }^{(3)}$ The manner of communication and interaction between the doctor and the patient has an effective role in patient satisfaction, treatment outcomes, medical expenses, and the quality of clinical services and even in lawsuits against doctors. ${ }^{(22-24)}$ in $70 \%$ of medical errors, there are problems related to doctor-patient re- lationship. ${ }^{(25)}$ Also, a significant percentage of lawsuits against doctors and incorrect application of healthcare directives is due to communication problems. ${ }^{(11)}$ Effective communication enables doctors to gather proper information and also helps them to encourage patients to follow a healthier lifestyle, and finally it reinforces the role of doctors in health promotion and disease prevention. ${ }^{(11)}$

The reflection of the growing emphasis on communication skills in the medicine and medical education can be observed in international statements, guidelines for medical schools and in education and professional medical standards. ${ }^{(22-24)}$ Comstock et al showed that there is a weak correlation between the practitioner's level of knowledge and patient satisfaction, while respecting the patient and allocating adequate time at the beginning of consultation to listen to the patient's problems have an important role in patient satisfaction. ${ }^{(26,27)}$ The results of another study by Roter et al showed that patients were more satisfied with the doctors trained in communication skills in comparison with the doctors in the control group, although this difference was not statistically significant. (17) It should be noted that establishment of a proper relationship by allocating adequate time, results in high patient satisfaction and encourages patients to perform the therapeutic instructions correctly and in a timely manner, accelerates the treatment progress and leads to reaching the main purpose i.e. healing the patients. ${ }^{(28)}$

Despite the efforts made by both groups of practitioners in the current research to assess the problem and to render a suitable strategy to the patients, lack of sufficient attention to the initial conduct, the necessary respect and allocation of adequate time to listen to the patients' statements regarding their current problem, may have resulted in decreased average interview duration in both groups. Moreover, the large number of the patients referring to clinics and the limited time for dentists to examine and listen to the patients' statements also influence this issue, but considering the importance of this allocated time in creating empathy, gaining patients' trust and cooperation and reaching 
suitable and satisfactory treatment outcomes, special attention is necessary in this regard. In a study by Rahman et al, the most weaknesses were related to the initial interview process, explaining the purpose of the interview and allocating adequate time to patients, which are in accord with our findings. ${ }^{(29)}$ Correspondingly, some studies have shown that work-related fatigue can disrupt doctors' judgment and capabilities and can result in unpleasant outcomes for patients. ${ }^{(30)}$

In the present research, a weak correlation in the dentists group and no correlation in the students group was detected between the level of education of the patients and the duration of their interviews. Whereas, in a research by Narenjiha et al which is also in accord with the study by Madani et al, it has been shown that patients with higher levels of education have had a better relationship with their practitioner and have been more enthusiastic and satisfied with presenting their current problem. ${ }^{(31,32)}$

However, Cramer et al found contradictory results. They found that patients with lower education levels showed more enthusiasm for speaking. ${ }^{(33)}$ The reason for this difference may be attributed to the type of the disease under study. In the study by Cramer et al chronic illnesses were evaluated, and in these cases due to repetitive visits and further familiarity, the practitioner tries to communicate with the patient according to the patient's level of education and understanding and also tries to obtain some information and render some explanations. ${ }^{(33)}$

In a study by Mogharab and colleagues also no significant correlation was detected between the patients' level of education and the level of satisfaction from doctors' communication skills. ${ }^{(34)}$ Despite the existing controversies among the results of different studies, it seems that it is necessary for the practitioner to become more familiar with the social and cultural characteristics of the patients and to establish a more effective relationship with them.

Correspondingly, in a meta-analysis performed to evaluate the effect of doctors' communication manner on treatment acceptance and presenting the problem by patients, it was observed that the chance of cooperation, speaking and treatment acceptance by patients was increased 1.62 times, when the doctors had been trained in communication skills. ${ }^{(35,36)}$
In a research by Makarem et al on the active listening capability of clinical professors, the statistical population was comprised of the clinical professors of Mashhad University of Medical Sciences. ${ }^{(37)}$ But in the present study, two groups of practitioners (students and dentists) were evaluated. In the research by Makarem et al, similar to the present study, demographic and confounding variables such as age, gender, and academic rank were evaluated regarding the professors and variables such as age, gender, education, income level, and the frequency of referrals were evaluated regarding the patients. ${ }^{(37)}$ The average age of the 30 doctors in the study by Makarem et al was 47 years. According to Mann-Whitney test, the average score of active listening was significantly higher among male physicians $(2.76 \pm 0.66)$ than among female physicians $(2.45 \pm 0.54)(\mathrm{p}<0.001$ and $\mathrm{z}=-3.790$ ).

Also, there was a significant negative correlation between the active listening score of the doctors and the number of scheduled patients. $(p<0.0004$ and $r=-0.20)$. The regression correlation between the two variables also showed that for each additional patient added to the list of scheduled patients, the average active listening score was 0.0007 decreased. Therefore, the observations indicated the overall low capability of listening to the patient's statements, which is in line with the results of the present study. ${ }^{(37)}$

These findings show that listening to the patients' statements by assigning adequate time is a learned skill, similar to other communication skills. Teaching communication skills during medical education is a new topic in our country, and only scattered activities limited to a few universities of medical sciences have been undertaken in this regard. Whereas, in many countries, teaching communication skills has been considered as a small investment with several achievements. ${ }^{(38)}$

By allocating adequate time to gather information regarding the patient's current problem, not only the patient feels that the doctor has listened and has understood him/her, but it also ensures the doctor of the accuracy of what he/she has deduced from the patient's statements. ${ }^{(37)}$

It seems that teaching these skills to physicians and dentists and focusing on reinforcing these skills by holding communication skills training workshops for doctors and other medical staff, 
and countrywide continuing education programs for physicians and dentists and by incorporating these skills in the students' curriculum, have an effective role in improving the quality of health services. ${ }^{(31)}$

\section{Conclusions:}

According to the results of the present study, it can be concluded that despite the efforts and multiple trainings regarding history taking and recording the patient's chief complaint, unfortunately dentists have not learned the importance of this issue yet and do not allocate adequate time to this important matter. Therefore, it seems that in line with previous attempts, necessary trainings must be performed and reinforced to change the dentists' attitude towards this subject and to help them realize the importance of the time allocated to the initial interview with patients.

This study has been derived from student thesis number ..... registered at the faculty of the dental school of Tehran University of Medical Sciences.

\section{References:}

1.Klitzman R. Improving education on doctorpatient relationships and communication: lessons from doctors who become patients. Acad Med. 2006; 81(5):447-53.

2.Ashbury FD, Iverson DC, Kralj B. Physician Communication Skills: Results of a Survey of General/Family Practitioners in Newfoundland. Med Educ Online [serial online] 2001;6:1. Available from URL Cited http://www.med-ed-online. org

3.Soltani Arabshahi S.K, Ajami A, Siabani S. Survey of Doctor-Patient Communication Skills Learning at Iran and Kermanshah Universities of Medical Sciences: Perceptions of Students, Interns and Faculty Members.RJMS2004;11(40):223230.

4.Emrich IA, Fröhlich-Güzelsoy L, Bruns F, Friedrich B, Frewer A. Clinical ethics and patient advocacy: the power of communication in health care. HEC Forum. 2014 Jun;26(2):111-24.

5.Greenberg MS. Glick M. Burket's Oral Medicine Diagnosis and Treatment. Orofacial Pain. 10th ed. BC Decker Inc., Elsevier India. 2003:310.
6. Hampton J R, Harrison M J, Mitchell J R, Prichard J S, Seymour C. Relative contributions of history-taking, physical examination, and laboratory investigation to diagnosis and management of medical outpatients .Br Med J. 1975; 2(5969): 486-489.

7.Eliav E. The importance of collecting patients' medical histories. Quintessence international 2012; 43(2):91.

8.Menzies R. Oral examination and charting: setting the basis for evidence-based medicine in the oral examination of equids. Vet Clin North Am: Equine Prac. 2013; 29(2):325-43.

9.Cassell EJ. Diagnosing Suffering: A Perspective. Ann Intern Med. 1999; 131(7) : 531-34.

10.Silverman J, Kurtz SM, Draper J. Skills for communicating with patients. Oxford, UK: Radcliffe Pub.; 2005;11-20.

11. Arora A, Cumming L, Crome P. Physician- facilitated designation to proxy decision maker. Isr J Health Policy Res. 2016;5: 28-32.

12.Ohtaki S, Ohtaki T, Fetters MD. Doctor- patient communication: a comparison of the USA and Japan. Fam Pract. 2003; 20(3): 276-82.

13.Sanson-Fisher R, Cockburn J. Effective Teaching Communication Skills for Medical Practice: Selecting an Appropriate Clinical Context. Med Educ 1997; 31(1) : 52-57.

14.Das M, Townsend A, Hasan MY. The Views of Senior Students and Young Doctors of Their Training in a Skills Laboratory. Med Educ 1998; 32(2) : 143-49.

15.Simpson M, Buckman R, Stewart M, Maguire P, Lipkin M, Novack D, Till J.Doctor-patient communication: the Toronto consensus statement. BMJ. 1991;303(6814):1385-7.

16.Robbins JA, Bertakis KD, Helms LJ, Azari R, Callahan EJ, Creten DA. The Influence of Physician Practice Behaviors on Patient Satisfaction. Fam Med. 1993; 25(1): 17-20.

17.Roter DL. Patient Participation in the $\mathrm{Pa}$ tient-Provider Interaction: The Effects of $\mathrm{Pa}$ tient Question Asking on the Quality of Interaction, Satisfaction and Compliance. Health Educ \& Behav. 1977; 5(4): 281-315

18.Kuehl SP. Communication tools for the modern doctor bag. Physician patient communication part 1: Beginning of a medical interview. J Community Hosp Intern Med Perspect. 2011 oct 17; 1(3): doi: 10.3402/jchimp.v1i3.8428 
19.Bartlett EE, Grayson M, Barker R, Levine DM, Golden A, Libber S. The effects of physician communications skills on patient satisfaction; recall, and adherence. J Chronic Dis. 1984 31;37(9):755-64.

20.Wasserman RC, Inui TS, Barriatua RD, Carter WB, Lippincott P. Pediatric clinicians' support for parents makes a difference: an outcome-based analysis of clinician-parent interaction. Pediatrics. $1984 ; 74(6): 1047-53$.

21.Hall JA, Roter DL, Katz NR. Meta-analysis of correlates of provider behavior in medical encounters. Med care. 1988;1:657-75.

22.Labaf A,Masoomi R,Raeiosi M. How long it takes patients'initial statements of concern. TUMJ 2015,73(8):608-13.

23.Makoul G. Essential Elements of Communication in Medical Encounters : The Kalamazoo Consensus Statement". Acad Med. 2001; 76(4): 390-393.

24.Aspegren K. BEME Guide No. 2: Teaching and learning communication skills in medicinea review with quality grading of articles. Med Teach. 1999 ; 21(6):563-70.

25.Symons AB, Swanson A, McGuigan D, Orrange $\mathrm{S}, \mathrm{Akl}$ EA. A tool for self-assessment of communication skills and professionalism in residents. BMC Med Educ. 2009; 9(1):1.

26.Comstock LM, Hooper EM, Goodwin JM, Goodwin JS. Physician Behaviors That Correlate with Patient Satisfaction. J Med Educ. 1982; 57(2): 105-112.

27.Comstock LM, Williams RC. The Way we Teach Students to Care for Patients. Med Teach. 1980; 2(4): 168-170

28.Harrington J, Noble LM, Newman SP. Improving patients' communication with doctors: a systematic review of intervention studies. Patient Educ Couns. 2004;52(1):7-16.

29. Rahman A. Initial Assessment of Communication Skills of Intern Doctors in History-Taking”. Med Teach 2000; 22(1-2): 184-88.

30.Nocera A, Khursandi DS. Doctors Working Hours: Can Medical Profession Afford to Let The Courts Decide What is Reasonable?. Med J Aust. 1998; 168(12):616-18.

31.Narenjiha M, Haghighat SH, Bahador $\mathrm{H}$, Shajari J, Haji Molla Hoseini F. Patient's Satisfaction from Doctor's Communication: a Survey in Ghods Clinic in Tehran. IJME. 2012; 12(1): 77-89
32.Madani G, Farzan A, Rabiee M. Patient satisfaction of medical and nursing services. Iran J Nur Mid Res. 2010 Aug 2; 9(3). Available at: http://www.ijnmr.mui.ac.ir/index.php/ijnmr/article/view/165>. Date accessed: 07 Aug. 2016.

33.Cramer EM. Significance tests and tests of models in multiple regression. American Statistician. 197;26(4):26-30

34.Mogharab M, Mahmoudirad Gh.H. Survey of patients' satisfaction from educational skill of nurses in medical and surgical units of ImamReza Hospital-Birjand. JBUMS. 2002; 9(1): 9-15 35.Zolnierek KB, DiMatteo MR. Physician communication and patient adherence to treatment: a meta-analysis. Medical care. 2009; 47(8):826842.

36.Kurtz SM. Doctor-patient communication: principles and practices. Can J Neuro Sci. 2002 Jun 1;29(S2):S23-9

37.Makarem A, Movaffaghi Z, Hosseini FS, Beiraghi N, Heshmati Nabavi F, Khaje Daluee M. Clinical Medical Teachers' Competency of Active Listening in Mashhad University of Medical Sciences. IJME. 2013;12(12):935-46

38.Zamani A, Shams B, Moazzam E. Communication Skills Training for Physicians as a Strategy for Enhancing Patient's Satisfaction: A Model for Continuing Education. IJME.2004; 4(1): 15-22. 